\title{
ESTUDO DE VIABILIDADE TÉCNICA E ECONÔMICA DE SUBSTITUIÇÃO DE PROCESSOS DE INJEÇÃO PLÁSTICA
}

\author{
Liliane Laye Rubin ${ }^{1}$ \\ Luiz Gustavo Dias Lopes ${ }^{2}$
}

Resumo: Com o constante crescimento na área automobilística as empresas vêm adotando estratégias novas a fim de reduzir seus custos e se manterem no mercado. O presente estudo visa analisar a viabilidade técnica econômica de dois processos de injeção plástica diferentes e verificar qual deles é mais viável para implementação dentro da organização. O método utilizado é um estudo de caso em uma empresa no ramo automobilístico, localizada no sul de Minas Gerais próximo aos três maiores e principais centros comerciais do Brasil. Os resultados evidenciaram que o processo no qual se deseja fazer tal substituição é viável, pois apresentou um retorno de investimento dentro daquele requerido pela empresa.

Palavras-chave: Competitividade; Processo de injeção; Redução de custo; Payback.

\footnotetext{
1 Graduanda em Engenharia de Produção/Centro Universitário de Itajubá - FEPI, Brasil. E-mail: lilica_arena@hotmail.com.

2 Doutor em Engenharia de Produção/Universidade Federal de Itajubá - UNIFEI, Brasil. E-mail: luizgustavo.lopes@yahoo.com.br.
} 